\title{
LO HUMANO Y LO ANIMAL. CONSIDERACIONES SOBRE LOS ESCRITOS RECIENTES DE W. WELSCH Y LOS ÚLTIMOS DE L. WITTGENSTEIN
}

\author{
Isidoro Reguera \\ Universitad de Extremadura (Cáceres)
}

\begin{abstract}
Resumen.- En la primera parte, este artículo analiza algunos escritos inéditos del Prof. Wolfgang Welsch (Jena), en los que éste intenta identificar el proprium humano (frente a lo animal) desde la teoría evolucionista. En la segunda parte, siguiendo en general las consideraciones de la primera, esboza una posible interpretación evolucionista de la filosofía de Wittgenstein, desde fuera de ella.
\end{abstract}

Palabras-clave.- evolución, círculo antrópico, lo humano, lo animal, cerebro, razón, trascendentalidad, condicionamientos biológicos, filosofía evolucionista

Abstract.- The first part of this article analizes some unpublished writtings of Prof. Wolfgang Welsch (Jena), where he tries to identify the human propium (in contrast to the animal) through the evolution-theory. The second part, following in general the considerations of the first, sketches a possible evolutionist interpretation of Wittgenstein's philosophy, outside of her.

Keywords.- evolution, antropic circle, the human, the animal, brain, reason, transcendental, biological conditioning, evolutionist philosophy

En noviembre de 2004 el Prof. Wolfgang Welsch pronunció dos conferencias en el Círculo de Bellas Artes de Madrid, cuyo contenido creo que respondía a un momento crucial en su pensamiento. En ellas avanzó ideas que ha ido desarrollando hasta hoy. Desde el recuerdo de aquel primer encuentro están escritas estas páginas ${ }^{1}$.

\footnotetext{
${ }^{1}$ Cito por el manuscrito de estas conferencias y por otros dos que posteriormente las desarrollan. Las dos conferencias de noviembre de 2004 pronunciadas en Madrid: (M1) "EPISTEMISCHER ANTHROPOZENTRISMUS. Genese, Versionen, Kritik der Denkform der Moderne", 28 pp. (No publicada aún). (M2) "INWIEFERN HEIDEGGER -BEI ALLER KRITIKDER MODERNEN DENKFORM VERHAFTET BLIEB. (Onto-Anthropologie statt HumanAnthropologie.), $24 \mathrm{pp}$. (Una versión de ella, sin las páginas finales, precisamente donde Welsch exponía sus puntos de vista evolucionistas de futuro, ha aparecido en castellano como "HEIDEGGER: ANTROPOCENTRISMO ONTOLÓGICO", en: Félix Duque, ed., Heidegger. Sendas que vienen, 2 vols., Madrid: Ed. Pensamiento, 2008, vol. 1, 84-113.

(M3) Crítica de Tomasello: "Just what is it makes homo sapiens so different, so appealing?" (10 pp.). Publicada mientras tanto con el mismo título en: DZPhil, Berlin 55 (2007) 5, 751-760.

(M4) Conferencia pronunciada en Bamberg el 4 de mayo de 2010: "Wie aus Natur Kultur hervorging" (15 pp.). (En vías de publicación).
} 
En el título de la gran mayoría de sus obras publicadas hasta entonces aparecen palabras que seguramente respondían a un espíritu filosófico interior: Widerstreit, Auswege, Grenzgänge, Undoing, Beyond; y, en el caso menos terminante: Transversalität, que, de todos modos, Welsch entiende como la forma crítica contemporánea de la razón. Seguramente el Prof. Welsch practicaba ya entonces la virtud nietzscheana de la "Redlichkeit", que hoy sigue encomiando: la buena costumbre de no dejar pasar un solo día sin plantearse siquiera una idea en contra de los pensamientos más queridos de uno mismo $(\mathrm{M} 3,5)$. (No digamos contra los de los demás.) Seguramente también sentía ya la tensión insostenible de los límites de ese mundo cerrado del antropocentrismo o -como él prefiere llamarlo por sus connotaciones semánticas, en cierto modo nuevas, tras la revolución copernicana"antropismo" moderno, que constituye desde hace 250 años al menos, tras Diderot claramente, el "Kokon" del pensar, o más bien su "Gefängnis", "Gummizelle", "Huis clos", su "Lähmung", "Sattheit", "Erstickung", "Trivialität", unido todo ello a una chocante "Selbszufriedenheit" (M3, 25, 2ss.).

Ni siquiera la razón transversal era capaz de desmoronar ese bloque moderno: ni la espesura de la subjetividad trascendental autocomplaciente ilustrada, ni la encerrona de las inacabables debilidades posmodernas del pensar. (Quizá sí pudiera hacerlo la razón evolutiva, evolucionista...) Y por lo que se refiere a la estética, a la teoría del arte, que Welsch siempre ha entendido primordialmente como originaria aisthesis, teoría de la sensibilidad, aristotélica: su decidida orientación sensible encerraba ya una vertiente biológica, que pusiera al día las condiciones básicas en que el ser humano siente realmente, fuera del círculo antrópico de cómo puede o debe sentir. Para una cosa y para otra, razón y sensibilidad, la transculturalidad posmoderna tampoco era una salida, era más bien un enredo en sus avatares, en un nuevo círculo: el de la innumerabilidad de sus diferentes juegos. El mucho colorido no hace más que ocultar mejor la palidez del fantasma, no porque muchos lo tengan se diluye el problema. Si para Welsch "die Leitfrage der Philosophie ist, wie es sich im Ganzen verhält" (M4, 14), había que hacer suelo en una nueva concepción general del ser humano que diera nueva luz a su acción y a su mundo de acción, ensombrecidos por escisiones de todo tipo, no sólo por la de razón/sensibilidad, o por la de identidad/diferencia, unidad/pluralidad, etc., sino, resumiéndolas todas, por la de humano/animal.

Había que plantearse nuevas cuestiones esenciales para seguir pensando con sentido en el ámbito que fuera. Definir de nuevo el concepto de conocimiento más allá del círculo antrópico y más allá de la escisión de que éste nace (como una especie de reacción esquizoide, podíamos decir): la contraposición y paralelismo entre subjetividad humana y objetividad natural. Y para ello había que preguntarse: ¿cómo definir de nuevo lo específicamente humano, más allá de la subjetividad, razón, lenguaje, etc., todos ellos conceptos semánticamente adulterados por una tradición esencialista que ya no puede ser en modo alguno de recibo dados los avances científicos? El ser humano no es un espíritu prisionero en un cuerpo, una razón presa en la sensibilidad, un lenguaje preso en sus juegos. Más bien es cuerpo, sensibilidad, juego inocente, o hay que pensarlo desde ahí, aunque nada más sea por intentar ver desde otra perspectiva: hay muchas características tenidas hasta hoy como especiales del 
ser humano que parece que no son sólo humanas, pero si ya no se puede recurrir en principio a una naturaleza especial del ser humano ¿cómo explicar, entonces, que consiga logros y avances que tan fuertemente lo distinguen de otros seres vivos? Cuestiones difíciles que parece que avocaban a un único camino de salida, único pero espléndido: la teoría de la evolución, y, más que la teoría de la evolución, sus datos. Camino que iniciaba una nueva pregunta: ¿hasta qué punto siguen actuando en el ser humano las consecuciones evolutivas y pueden dar pautas para una nueva comprensión característica suya y de su conocimiento? $Y$ una hipótesis: el ser humano ha emergido de una larga historia de 7 millones de años, sólo se le puede comprender evolutivamente; el conocimiento objetivo del ser humano sólo es posible porque la evolución de sus condiciones cerebrales pertenece al desarrollo evolutivo del mundo, se ha desarrollado con él ${ }^{2}$. Se trataba simplemente de tomar en serio al homo sapiens, no al animal rationale (ni al homo animalis) de la tradición metafísica (o salvajemente científica).

Por lo que puede apreciarse por sus publicaciones, parece que más o menos desde el año 1998, en que toma posesión en Jena de su cátedra de "filosofía teórica", el Prof. Welsch busca salidas menos teóricas de su mundo filosófico: genésicas y genéticas, evolutivas en cualquier caso ${ }^{3}$. Y no explicaciones evolucionistas especulativas, o esencialistas, como las que achaca en 2007 a Tomasello. "Allein genetische Befunde und Überlegungen vermöchten aus der Sackgasse herauszuführen" ${ }^{4}$. Salidas, insisto, del callejón sin salida de la modernidad y de la posmodernidad, del antropocentrismo moderno y del desconcertante espectro transcultural posmoderno de rupturas, diferencias, indiferencias, debilidades, rizomas, autolegitimaciones, relatos, juegos, etc., que había descrito magistralmente en su "transversale Vernunft". Auswege, o Undoings, no sólo de la razón, como veremos, sino también de la sensibilidad, liberando a la estética de viejas ataduras culturales y proporcionándola nuevo sentido de futuro ${ }^{5}$ Esas salidas de Sackgassen o liberaciones de Gummizellen

\footnotetext{
${ }^{2}$ Estos eran los planteamientos y objetivos del grupo de investigación "Interdisziplinäre Anthropologie: Fortwirken der Evolution im Menschen - Humanspezifik - Objektivitätschancen der Erkenntnis" (EHO) (vom BMBF gefördert), que el Prof. Welsch constituyó y dirigió de 2006 a 2009 y cuyos resultados se publicarán en la primavera de 2011.

${ }^{3}$ Un momento crucial en ese paso evolutivo parece ser su estancia en Stanford en el año 2000 y las vivencias intelectuales de sus paseos solitarios de entonces por las playas del Pacífico, en los que, ante la contemplación del mar, peces, aves, movimiento incesante, sonoridad vital, se imponía -quasi místicamente- un pensamiento: "wir alle sind zusammengewachsen" ("todos hemos crecido juntos"). Cfr. "Reflecting the Pacific Ocean" (http://www2.unijena.de/welsch/)

${ }^{4} \mathrm{M} 3,10$; DZPhil. 55,5, 758 .

${ }^{5}$ Como no vamos a referirnos más a ello, dejemos constancia suya, sin embargo. En un paper (29 pp.) entregado al XVI International Congress of Aesthetics (Río de Janeiro, julio 2004), que se puede encontrar en su página web (http://www2.uni-jena.de/welsch/), titulado "Animal Aesthetics" y basado en principio en Darwin, Welsch insiste en la "turn to transhuman aesthetics" que ya llevaba sugeriendo hacía algunos años. Si lo humano en general sólo se puede entender hoy en un contexto más amplio que el humano, también la estética, es decir, la sensibilidad humana a la base de esa Sinneslehre. ¿Cómo? "Teniendo en cuenta, por ejemplo, nuestro lugar en el entorno cósmico y natural, o nuestra conectividad primordial con el mundo, o los estratos no-humanos de nuestra existencia", escribe remitiendo a un artículo suyo publicado cuatro años antes ("Art Transcending the Human Pale - Towards a Transhuman Stance", 2001) (1, cfr. 18). No la estética refinada de un Picasso, por ejemplo, pero sí "la actitud estética como tal" se ha originado en el mundo animal y luego la evolución cultural la ha refinado en nosotros. La base originaria de la estética va mucho más allá de la Grecia clásica,
} 
son escapes a una nueva Lichtung menos vacía que la heideggeriana, mucho más movida que la absorta espera al ser en ella: se sale a la oscuridad luminosa de los genes, a la multimillonaria evolución desde lo salvaje hasta lo humano, superando toda Selbstzufriedenheit racionalmente esencialista, antrópica y sensiblemente edulcorada.

¿Puede así resumirse, a grosso modo, la evolución del pensamiento de Wolfgang Welsch? Así me la imagino yo, al menos. De lo hecho desde su evolutional turn, más o menos desde el año 2000, ha publicado aún poco, pero pronto habrá de aparecer en tromba. Cuando el Prof. Welsch estuvo en Madrid yo andaba ocupado con el concepto de "lo animal" en el Wittgenstein último de Über Gewissheit. Y tanto la crítica al pensamiento moderno como "antropía", cuya génesis analizó en la primera conferencia, como las "Andeutungen" sobre evolucionismo que curiosamente dejó para el final de la segunda (sobre el humanismo no superado de Heidegger), me resultaron muy cercanas. Esa cercanía es el mejor requisito para entender a alguien. Espero haberlo hecho hasta ahora, y seguir haciéndolo en lo que sigue.

\section{Lo humano. (El camino de Welsch al proprium humano)}

Los temas que plantea una evolución intelectual así, incluso aunque sólo fuera imaginaria, son no sólo de sumo interés y de máxima actualidad, sino de extrema urgencia para poder siquiera seguir pensando en filosofía (o no hacerlo). Haya exagerado o no la Modernidad con su humanismo, la pregunta "¿qué es el hombre?" sigue siendo básica y central en filosofía (y no sólo en

digamos, pero hace honor a su etimología griega: la sensación (propiedad elemental de los animales, seres sintientes frente a los racionales), es decir, la sensibilidad animal y el básico placer sensible que produce, son la condición elemental del gusto y juicio estéticos, de las capacidades emocionales e intelectuales estéticas. Desde una perspectiva evolucionista está claro que el hedonismo es la base de la estética. El análisis preestético de la evolución del placer y la localización de su base neuronal pueden darnos un mejor conocimiento, un conocimiento genealógico y genético, de la constitución de la estética. (cfr. 15)

Constitución que, en ese sentido, desarrolla años después en "Von der universalen Schätzung des Schönen" (Melanie Sachs \& Sabine Sender, eds., Die Permanenz des Ästhetischen, Wiesbaden: Verlag für Sozialwissenschaften, 2009, 93-119), en forma, podíamos decir con él, de una "gramática neuronal" de la belleza y de la universalidad de su experiencia. Expone la base -y en torno a ella la explicación- neuronal de patrones generales de belleza y de tipos universales de experiencias suyas: en paisajes y cuerpos o en la gran belleza que impresiona (Taj Mahal, Mona Lisa, novena sinfonía de Beethoven, por ejemplo). Cada una de esas experiencias (y preferencias) estéticas tienen una base cerebral característica, dependiente de la permanencia de la correspondiente dotación genética, son experiencias configuradas y seleccionadas en la filogénesis, y en todos los casos podría valer (en serio y menos serio) la tesis tópica general de la neuroestética: que la belleza es propiamente brain-happiness. Welsch escribe sobre esta tesis: "Sie könnte trivial erscheinen - ist es aber nicht. Man überlege nur einmal, wie anders man Kunstausstellungen und Museen nutzen wird, wenn man dieser These vertraut. Man wird sie nicht mehr als Andachtstempel ansehen oder als Sonntagnachmittagspflicht aufsuchen, sondern man wird sie als Training-und Fitnesszentren für das Gehirn nutzen: zum Zweck des Bezetzungsumbaus, zur Erzeugung neuer Verbindungen, für Integralerregungen. Oder einen Sonatensatz wird man nicht mehr als historische Kuriosität nachforschen, sondern man wird ihn auf das hin abhören, was er mit unserem Gehirn macht..." (110-111). 
filosofía, desde luego). De ella sigue dependiendo todo: pero ya no circularmente (del círculo del pensar sacan los datos) sino en línea (evolucionista). Hoy se tienen datos más que metafísicos para comenzar a plantearla de una vez con sentido. De modo que la tarea de buscar lo característico, definitorio, peculiar, esencial, específico o propio del ser humano es una tarea primordial. La que se propuso Welsch.

\section{(encierro antrópico)}

Welsch piensa que la Modernidad sí ha exagerado. Su principio es lo que él llama el "axioma antrópico", decíamos (formulado por Diderot en la Enciclopedia en 1755 y legitimado epistemológicamente por Kant en la Crítica de la razón pura en $1781^{6}$ ). Comentando a este último, Welsch deja bien claro el objetivo a batir: "All unsere Gegenstände sind grundlegend duch die apriorischen Formen des menschlichen Erkennens (Anschauungsformen und Kategorien) bestimmt. Daher können wir in unserer Erfahrung nur menschlich geprägten Gegenständen begegnen und darüberhinaus auch andere Gegenstände (Ding an sich, Gott, etc.) nur menschlich gefärbt imaginieren. 'Wir können nicht anders als zu antropomorphisieren' - 'Wir machen alles selbst'. Die Welt ist eine menschliche und darin eine geschlossene Welt. Der Mensch bildet das Mass der Welt" (M1, 1). Extraño que aquellos modernos, a pesar de sus ilusiones revolucionarias, no se dieran cuenta del encierro que esto supone, y más extraño aún que los que los siguieron hayan permanecido y permanezcan inconscientes, cuando no conscientes y autosatisfechos, de ello. Que no les haya entrado hartura (Sattheit) de tanta presunción, cuando el desventurado ser humano es manejado por la vida y el destino como no quiere, a pesar de toda su volátil epistemología trascendental. Es la vida la que impone los conceptos, decía Wittgenstein (es el mundo el que los impone, podemos decir ahora evolucionistamente). O los impone el poder, la ideología, la moda... y muchas cosas más. Pero todo ello es algo obvio, sólo las lumiéres modernas pudieron obcecarse y no ver detrás de todo ello más que un sujeto trascendental. Que el mundo es mi mundo es obvio, pero que el mundo no es mi mundo también.

Desde la época ilustrada, en efecto, el pensar moderno se ha encerrado definitivamente en sí mismo: nada hay que no esté condicionado por el pensamiento o la sensibilidad humana, por la lógica trascendental o la estética trascendental del ser humano. Nadie sale de ese axioma, ni siquiera quienes

\footnotetext{
${ }^{6}$ Cuyas versiones Welsch va recorriendo en M1 hasta la actualidad en sus ejemplos máximos: Feuerbach, el historicismo, Nietzsche, las ciencias humanas y culturales de hoy y la filosofía analítica; viendo cómo incluso críticos suyos no acaban por salir de su círculo: Frege, Russell, Husserl, Foucault, Heidegger (cuyo caso expone con todo detalle a parte, en M2). Welsch, con rapidez, más bien insinuando todo, consigue llevar ese encierro a un extremo de tensión en que la autosatisfacción con la que incluso se asume resulta ya grotesca y él mismo se diluye por su propia trivialidad e inconsistencia. Por cierto, la formulación de Diderot, origen explícito de todo y que define programáticamente el antropocentrismo moderno, distinguiéndolo de otras versiones anteriores, es ésta: "L'homme est le terme unique d'où il faut partir, \& auquel il faut tout ramener" (cfr. M1, 3ss.). Como "perfekte epistemologische Legitimation" de ella Welsch cita el párrafo B XVI del prólogo de 1781 de la KRV de Kant (ed. 1787)(cfr. M1, 6ss.)
} 
no lo aceptan, escribe Welsch, y cita, justificándolo, a Nietzsche, Frege, Husserl y Foucault, como decíamos. Y sobre todo a Heidegger, sobre el que trata, en este sentido, toda su segunda conferencia de Madrid (M2). Este encierro en la forma de pensar antrópica es empobrecedor, paraliza incluso el pensar, insistimos con Welsch.

El anthropos es el comodín de respuesta para todo: "Se sabe siempre la respuesta a todas las preguntas: 'es el ser humano'. Esa trivialidad ahoga el pensar en lugar de darle aliento" (M1, 25).

(salida evolutiva)

Pero es posible salir de este depauperante encierro moderno, piensa Welsch. Para ello parte radicalmente de la hipótesis de que es falso de plano el supuesto antrópico de que "sólo podemos construir un mundo pero no conocer el mundo". ¿Falso por qué? Porque es inconsistente: está formulado desde una perspectiva incondicionada imposible. Porque confunde condiciones de acceso con condiciones de validez: que se tenga acceso cognoscitivo a algo no quiere decir que se lo condicione realmente. Y porque la inmunidad, incluso autosatisfacción, que muestra la modernidad frente a esa incongruencia de base de su pensar, que parece no importarle, no es sintomática de racionalidad sino sospechosa de ideología. Esto es algo que realmente parece molestar a Welsch, y no es extraño: dígase lo que se diga en plan crítico (inconsistencia, confusión o sectarismo ideológico) no tiene repercusión alguna, los modernos no se dan por enterados. Parece que la cárcel es para ellos un refugio seguro.

Welsch, ante ello, intenta esclarecer, primero, la génesis (desde Diderot) de esa obstinada forma moderna de pensar y plantea, después, una crítica y superación suya. Eso hizo en Madrid en 2004. Demos por supuesta la historia de la génesis de ese empecinamiento, que puede seguirse en M1. ¿Cómo esbozó o "insinuó" Welsch en Madrid el camino que ha seguido después hacia una imagen del ser humano diferente de la antropocéntricamente cerrada? Lo hizo bajo dos criterios programáticos. Primero: esa imagen ha de tener en cuenta la evolución y su influjo permanente (Fortwirken) en nosotros, de modo que contemple retrospectivamente la historia entera del ser y no un corto episodio textual suyo, como sucede en Heidegger. Segundo: ha de tener en cuenta que los patrones evolutivos con los que nos relacionamos con el mundo han nacido ya de él, en interacción con él, de modo que ya están a priori acomodados a sus estructuras fundamentales; que en el a priori ya está inscrito el mundo, que el modo de operar de nuestro cerebro ya está en principio en correspondencia con esas estructuras, como parecen mostrar los avances de la neurobiología. Tanto desde un aspecto como desde otro -que no son más que dos vertientes de lo mismo- la imagen del ser humano se transforma, se transforman las condiciones de objetividad de su conocimiento, la relación yo y mundo es otra y, en general, la concepción antrópica desaparece junto con su inconsiderada autosuficiencia ${ }^{7}$.

\footnotetext{
${ }^{7}$ Cfr. para lo dicho hasta ahora en este apartado: M1, pássim y M2, 22s.; para lo que sigue: los manuscritos 3 y 4 .
} 
Lo que era sólo una "Andeutung" en Madrid se ha ido y se va convirtiendo en una realidad mientras tanto. En septiembre de 2007 Welsch realiza una tan clara como respetuosa crítica a Michael Tomasello ${ }^{8}$, en la que aparecen también claros sus propios puntos de vista. Los progresivos desplazamientos de Tomasello, forzados por los nuevos descubrimientos, en la detección de lo humanamente específico, que van de la intencionalidad individual a la compartida y a la colectiva, por decirlo rápidamente, y su definitivo fracaso en localizarlo hacen reflexionar a Welsch y lo llevan a consolidar su propio camino. ¿Es posible captar ese specificum humano? ¿No sucederá siempre lo mismo que le sucede a Tomasello, de modo que la búsqueda del proprium humano, y de la salida del pensar antrópico moderno por una nueva definición de lo humano, devenga una tarea absurda? (Quizá lo humano pueda definirse por el devenir-humano mismo...) Quizá el que ese proceso amenace con ir al infinito se deba a que la perspectiva desde la que se plantea es equivocada y haya que tomar otra completamente diferente. Puede ser que la tesis de Tomasello, que sustenta todo su trabajo, de que hay un (único) specificum humano sea errónea. Parece -extrañamente en un científico de su talla- que se acerca a posiciones esencialistas sobrepasadas: no se trata de diferenciar al ser humano por una sola capacidad (razón, lenguaje) como se hacía antes, tampoco su naturaleza se basa en una única adaptación biológica, como cree Tomasello, adaptación casi sobrevenida del cielo como una causa o una qualitas occulta, según los nuevos descubrimientos hay que apostar por la gradualidad y procurar entender cómo de una estructura dada emerge una nueva. La explicación de Tomasello no sería realmente evolucionista, se limitaría a constataciones fácticas de diferencias con los animales. Resulta extraño que Tomasello pase por alto que los orígenes de nuestra cognición y condición cultural no son a su vez culturales, que lo propio del ser humano hay que buscarlo en la evolución protocultural, explicarlo desde ella, explicar su génesis, es decir, no sólo constatar las diferencias con el animal sino explicarlas evolutivamente. "Kulturell agieren wir ein protokulturell entstandenes Potential aus", escribe Welsch ${ }^{9}$.

Tampoco después de estas consideraciones críticas de Welsch queda claro qué sea el ser humano: ¿algo que en el curso de la evolución se ha hecho así como es, un ser especial? Eso es hablar en razón pero decir poco. Lo ideal sería, escribe Welsch, que se unieran los análisis psicológico-fácticamente orientados de Tomasello con explicaciones genuinamente evolucionistas y se superara con ello la impresión de querer asignar al ser humano una peculiaridad esencialista. "Dann würde endlich begreifbar, wie der Mensch im Zug der Evolution zu dem besonderen Wesen geworden ist, als das wir leben"10.

\footnotetext{
${ }^{8}$ Crítica referida sobre todo a su obra: The Cultural Origins of Human Cognition, Harvard University Press, 1999. (Die kulturelle Entwicklung des menschlichen Denkens. Zur Evolution der Kognition, Frankfurt a/M: Suhrkamp, 2002.) (Los orígenes culturales de la cognición humana, B.Aires, Amorrortu 2007.)

${ }^{9} \mathrm{M} 3,10$; DZPhil 55, 758.

${ }^{10}$ Id.
} 
(la evolución cultural acumulativa como proprium humano)

Con esa perspectiva Welsch sigue su camino a lo propio del ser humano en la conferencia de Bamberg de agosto de 2010. Dejando claro, primero, la sinrazón del esencialismo en su mayor ejemplo: el de la racionalidad, que fue el distintivo más socorrido adscrito al ser humano desde antiguo (animal rationale). Por los descubrimientos de hoy puede decirse que ningún elemento de la racionalidad (conceptualización, cálculo, ponderación, etc.) es exclusivo del ser humano, nuestra racionalidad representa un desarrollo posterior de la racionalidad animal: "Nichts von dem, was wir beim Menschen finden, ist eine absolute Novität, die mit der Ankunft des Menschen plötzlich vom Himmel gefallen wäre, sondern es handelt sich bei alledem um Weiterentwicklungen von prähuman schon Hervorgebildetem" (M4, 2). No por eso somos nada más que animales o primates, en nuestras prestaciones culturales somos claramente diferentes de los demás seres vivos. "Der Generalnenner dieser den Menschen unterscheidenden Leistungen lautet 'Kultur'. Der Mensch ist das Kulturwesen par excellence - und eben dadurch von den anderen Lebewesen unterschieden" (id.) (Un primer paso al proprium humano: el ser cultural por excelencia.)

Aunque ciertamente en el reino animal se encuentra cultura (configuraciones estatalizantes, formas de comunicación ingeniosas, uso, invención de herramientas, etc., técnicas culturales en general), lo que falta en él es el "desarrollo cultural acumulativo" que ha conducido al ser humano a esa evolución cultural gigantesca que le diferencia tan claramente de sus convivientes. Somos seres especiales, pues, pero no se consigue encontrar un factor distintivo, exclusivamente humano. Será porque buscamos mal... A la vista de los factores de continuidad que se van descubrimiento la tarea es otra que la esencialista: "eine neuartige Erklärung der menschlichen Besonderheit zu finden, die nicht auf einen Sonderfaktor setz, der beim Menschen irgendwoher hinzugekommen wäre, sondern die strikt davon ausgeht, dass unseren Vorfahren auf dem Weg der Menschwerdung gar kein anderes Startkapital zur Verfügung stand als das unseren nächsten Verwandten ebenfalls zur Verfügung stehende Kapital". Y para ello la apasionante pregunta es: "wie dieses prähuman Startkapital beim Menschen im Verlauf der Hominisation eine Ausrichtung annehmen konnte, die ihn schliesslich zu den eindrucksvollen Leistungen der kulturellen Evolution befähigte" (id., 2-3).

Welsch recorre para evidenciarlo, según el estado actual de la cuestión, las tres fases en el desarrollo evolutivo desde la separación de australopitecus y chimpancés hasta el ser humano de hoy: la de los homínidos, la del homo homo y la del homo sapiens, digamos, poniendo de relieve en cada una los hitos evolutivos más importantes e impactantes. Una historia de 7 millones de años: ca. 4 millones y medio de período de hominización, ca. 2 millones y medio de período protocultural y ca. 40.000 años de período cultural. Somos muy viejos. En la Grecia clásica, desde luego, no sucedió la epifanía de la ratio universalis, y menos sucedió por manía divina o por obra del daimon filosófico, como se dice a veces. Incluso el hito evolutivo cultural más reciente, el de la aparición de las grandes culturas, tuvo lugar hace 6.000 años. Aunque 
evolutivamente no son distancias relevantes, para la común historia del pensar son demasiado.

Hasta hace 40000 años no podemos encontrar nada distintivo del ser humano. Ni siquiera el cerebro -formado antes- nos distingue de los animales, no es propio del ser humano. Einstein concibió la teoría de la relatividad con un cerebro paleolítico, efectivamente. A partir de entonces las prestaciones culturales del ser humano comienzan a acumularse de tal modo y a tal velocidad que deja a sus congéneres detrás. (El cerebro ya no se desarrolla biológicamente.) Si hay que encontrar diferencias relevantes (diferencias culturales) con el animal tiene que ser en el tercer período, en el que domina ese "ser cultural por excelencia", como hasta ahora hemos caracterizado de más cerca al ser humano. Un ser cultural por antonomasia y por antonomasia acumulador de cultura, y tanto una cosa como otra en devenir siempre.

Para que el desarrollo cultural acumulativo pueda darse, esté en devenir constante y no se produzca estancamiento, hacen falta ciertos mecanismos que también son diferenciales del ser humano. Mecanismos de instrucción y aprendizaje rápidos, precisos, económicos, que garanticen el equilibro entre indentidad y diferencia, tradición e innovación en el todo evolutivo de una cultura: la capacidad de imitación, variación e innovación humana y de asentar el devenir cultural en instituciones culturales vivas y perdurables. Muy interesante es la alusión a la escritura como el más habitual de los "WildwuchsStornierungssysteme" (sistemas de neutralización del crecimiento salvaje) (M4, 12). La institución de la escritura garantiza, por una parte, la exactitud de copia, la reproducción idéntica, es decir, la identidad. Por otra, es el substrato del sentido: en ella el sentido se independiza de la letra; y con el sentido -la puerta de la hermenéutica- viene la diversidad y la diferencia: de un mismo texto pueden deducirse cosas completamente diferentes. El sentido es el producto nuclear de una cultura en tanto supera en la diferencia la identidad cultural desde ella misma. En el fondo toda cultura es hermenéutica.

Y en la dialéctica cultural humana de identidad y diferencia, aparece un exponente más en el camino hacia lo humano: la generalidad es el último paso a la peculiaridad del ser humano. El ser humano es un generalista, escribe Welsch, tiene capacidad de abstracción, que puede extenderse a cualquier ámbito posible sin quedar limitada a aspectos relevantes para el mundo de la vida. El cerebro humano se ha convertido en un aparato de adaptación generalizada: en una máquina universal de solución de problemas, en "eine generelle Problemlösungsmaschine", escribe Welsch. Así que característico del ser humano es no sólo el desarrollo progresivo de capacidades concretas, sino, sobre todo, su poder de reorientarlas siempre en dirección a la generalidad. Las capacidades prehumanas se han liberado humanamente de su atadura a la esfera de salida y se han expandido más allá de ella. "Menschen sind Primaten, die sich zu Generalisten entwickelt haben" (M4, 13).

La generalidad es el último paso en el camino a la peculiaridad del ser humano en tanto es el motor básico inventivo de la acumulación: en cuanto permite transposiciones de solución de problemas de un ámbito al otro, así como combinaciones nuevas de patrones de procedimiento, se encarga de la 
creatividad y el progreso, del cambio de paradigmas. "So fusst der kumulative Charakter der kulturellen Evolution insgesamt auf der humanspezifischen Generalitätstendenz / Flexibilität und der aus ihr erwachsenden Tendenz zum Überschreiten des status quo" (Id., 14). Éste es el paso definitivo de Welsch al proprium humano, que, dentro del equilibrio entre identidad y diferencia, tradición e innovación, queda así claramente encuadrado: flexibilidad cultural acumulativa, capacidad de innovación por generalización en la acumulación cultural. Y, en este sentido, la evolución cultural acumulativa es definitivamente el proprium humano.

Un desarrollo cultural acumulativo, en cualquiera de los sentidos vistos hasta ahora, y por tanto una auténtica evolución cultural, tanto dentro del curso (Gang) de una cultura como en el trans-curso (Übergang) de ellas, sólo se encuentran en los seres humanos, seres eminentemente culturales. "Eine auch nur annähernd vergleichbare kumulative Entwicklung ist nirgendwo im sonstigen Tierreich -auch nicht bei unseren nächsten Verwandtenfestzustellen. / zu finden" (Id.) Welsch acaba brillantemente esta conferencia de Bamberg, que casi he vuelto a repetir yo en estas líneas ${ }^{11}$, aludiendo a Darwin el último responsable de todo- en el bicentenario de su nacimiento. La demostración de Darwin de que el ser humano proviene del reino animal no es un agravio a la condición humana, como pensaba Freud (o pensaría Heidegger). A Welsch le parece todo lo contrario. "Die evolutionäre Betrachtung zeigt: Die Menschen sind sehr besondere Wesen, weil nur bei innen aus dem gemeinsamen prähumanen Erbe etwas so Besonderes geworden ist; und sie haben in gewissen Sinne diese ihre Menschwerdung selber betrieben. Ein solches Wesen aber, das aus so bescheidenen Anfängen so besonders geworden ist, muss man doch wohl mehr bewundern, als eines, das nur aufgrund einer fremden Gabe und ohne eigenes Zutun eine Besonderheit aufweist. Die evolutionäre Betrachtung fügt uns und unserem Selbstbewusstsein gerade keine Kränkung zu, sondern kann, ganz in Gegenteil, eher Anlass zur Bewunderung bieten" (Id., 15)

Lo humano: flexibilidad cultural acumulativa del ser cultural por excelencia. ¿Y lo animal?

\section{Lo animal. (Lo místico del último Wittgenstein)}

En las páginas que he comentado Welsch nunca contempla explícitamente los delirios metafísicos que ha generado un cerebro autorrecurrente, generalizante, su flexibilidad especulativa. Tampoco la tensión en que puede vivir intelectualmente un ser humano que utiliza seriamente esa desmesurada capacidad autorreferencial del cerebro (10 millones de veces superior a la de referencia al exterior). Ambas cosas también pertenecen a la cultura y a la experiencia de su creación, y por tanto a la evolución cultural de la razón y de

\footnotetext{
${ }^{11}$ Que el interés de este M4 y el hecho de que no esté aún publicado disculpe en lo posible la simple narratividad, literalidad incluso, de mi comentario, que, por estas razones, no ha querido ser interpretativo ni crítico, sino simplemente descriptivo. En adelante será otra cosa.
} 
la sensibilidad humanas. Lo animal, frente a ello, representa mesura y paz. Es decir: bien la retroevolución (imaginaria) del ser humano a estadios prehumanos o protoculturales, incluso homínidos (hay para elegir un abanico de 7 millones de años), o bien la permanencia (de hecho), latentemente activa en la forma que sea, de huellas de etapas prehumanas en general en el ser humano, pueden disolver entusiasmos especulativos, en un sentido, y proporcionar paz al pensar, en otro. Todo esto tómese sin exageración ni ampulosidad. Sí es posible imaginar -humanamente, desde luego- el estado de la condición protorracional prehumana (de que gozábamos, evolutivamente hablando, hace más de 40.000 años). Y es un hecho que eso da paz al pensar. La mejor prueba eficiente de ello -sin datos evolutivos- es Wittgenstein.

Ahí enmarcaría yo, desde el mundo intelectual de Welsch que he descrito, las pocas pero impactantes referencias del último Wittgenstein a lo animal (o a lo infantil) en las páginas de Über Gewissheit. Es difícil encontrar una consideración más seria, profunda y respetuosa de lo animal (desde lo humano, insisto). Esa seria y sobria consideración wittgensteiniana de lo animal (la definitiva seguridad del saber es algo que está más allá de lo fundado y lo infundado, y en cuanto tal puede concebirse como "algo animal"12) no tiene nada que ver explícitamente con la evolución. Wittgenstein no era un evolucionista, como es sabido no le entusiasmaban las cuestiones científicas sino las conceptuales y estéticas. En este caso, consideraba a Darwin un grande, lo nombra al lado de Copérnico diciendo que ambos no habían descubierto una teoría verdadera (algo absurdo), sino un nuevo aspecto fructífero de considerar las cosas (lo más que se puede lograr racionalmente). De todos modos pensaba que el descubrimiento de Darwin no tenía influjo especial en la filosofía ${ }^{13}$.

¿Por qué Wittgenstein (y Heidegger) ahora? En la segunda conferencia de Madrid de 2004 (M2), como ya he dicho, el Prof. Welsch expuso la tan poética como evanescente consideración del ser humano de Heidegger, que menosprecia lo animal en nombre de un humanismo orientado al ser que no supera el antropismo. Al escucharle yo pensaba a la vez en la opción dispar wittgensteiniana, que por fin he podido explicitar -después de tanto tiempo- en noviembre de 2010 precisamente en Jena y desde la perspectiva o el contrapunto, otra vez, de las posiciones de Welsch. De ahí que asomen ahora tanto Wittgenstein como Heidegger. Al fin y al cabo se trata de los dos más grandes filósofos tras Nietzsche, incluso podíamos decir postnietzscheanos (más que evolutivos, destructores). La salida o el punto de fuga del encierro antrópico para ninguno de los dos fue la evolución misma: para Heidegger fue lo ontológico ( $y$ en tal caso una historia reducida del ser), para Wittgenstein lo animal (sin historia). (Welsch ha estudiado lo primero en $\mathrm{M} 2$, yo estudiaré ahora lo segundo.) Desde este punto de vista podría plantearse esta cuestión propedéutica meramente retórica, es decir, que no espera respuesta teórica,

12 Cfr. ÜG \&\&357-359. ÜG (Über Gewissheit), se cita por el número de parágrafo. VB (Vermischte Bemerkungen, Frankfurt a. M.: Suhrkamp, 1977), se citan por la página de esta edición. TR (Tractatus logico-philosophicus), se cita por la numeración de sus proposiciones. PU I (Philosophische Untersuchungen, primera parte), se citan por el número de parágrafo. TB (Tagebücher 1914-1916), se citan por la fecha en que esté escrito lo citado.

${ }^{13}$ Cfr. VB 42, TR 4.1122. 
porque no la hay, y sólo pretende conseguir ver desde otro aspecto todo lo escrito hasta ahora (o con todo lo escrito hasta ahora ver desde otro aspecto lo animal wittgensteiniano): ¿lo propio del ser humano está en la línea del "ser" de Heidegger o en la de "lo animal" de Wittgenstein? El contexto de la pregunta en primer plano: Heidegger no salió del encierro antrópico, Wittgenstein sí. En segundo: el punto de vista evolucionista es incompatible con el de Heidegger y no es incompatible con el de Wittgenstein. Así señalamos camino... Aludamos, primero, brevemente al Heidegger "madrileño" de Welsch.

\section{(Heidegger)}

Heidegger habría rechazado de plano como algo prefilosófico el punto de vista evolucionista. Para él simplemente era irritante nuestra "kaum auszudenkende abgründige leibliche Verwandschaft mit dem Tier", como la llamaba, queriéndonos hacer creer que la esencia de lo divino resulta más cercana al ser humano que lo insólito de los animales. "Das ist nur noch schlecht weltanschaulicher (nicht einmal mehr philosophisch zu nennender) Unsinn", concluye Welsch $(\mathrm{M} 2,22)$. Frente a ese odioso parentesco animal, Heidegger pretende explicar el ser humano por su referencia al ser, pero no sale del antropismo: al hacer de esa referencia la esencia más íntima de lo humano lo único que consigue es ontologizar ésta, es decir espesarla metafísicamente, y con ella el antropocentrismo. No se sabe en definitiva si el ser humano es el ser o el ser es el ser humano: el ser constituye el pensar humano pero no piensa nada sin ese pensar, la referencia al ser constituye la esencia del ser humano pero el ser no tiene más referencia que ésa, etc. Heidegger no sale del círculo humanoide más que ahondando en él.

Y ello porque la referencia esencial al ser ya está fundada ella misma en una concepción ad hoc de la esencia: como "éxtasis" del ahí (del ser) o "excentricidad" del centro (del ser humano). La salida desde la esencia no deja de ser esencial, por muy excéntrica que sea la esencia esa excentricidad es suya, la esencia sigue siendo el centro y la referencia del centro no es salida, no es más que referencia sin fin.

Heidegger admitió su antropocentrismo, pero lo calificó también -también ad hoc- de "excéntrico", creyendo quizá sinceramente que con ello siquiera decía algo: una excentricidad concéntrica, o más bien al revés. Permanece hundido en la concéntrica vorágine de la hermenéutica histórica de tópicos que él mismo quiso destruir. (Justamente lo contrario es el rasgo distintivo de Wittgenstein.) Se cambia de nombre, pero dentro de la cajita el escarabajo sigue siendo el mismo, o la que sigue siendo la misma es la cajita y el escarabajo el que cambia, que da igual. Parece que Welsch lo prefiere así. "Er hat das alte Privileg des animal rationale durch das neue des Partners ('Nachbarn', 'Hirten') des Seins ersetz. Der Inhalt hat sich geändert, die Struktur ist geblieben" (M2, 21).

A pesar de referencias, excentricidades y éxtasis Heidegger no va más allá del horizonte de lo humano, concluye Welsch, queda recluido, digamos, en ese pegajoso esencialismo de la teoría moderna de lo humano. Y en ese círculo - 
que él llama "Lichtung"- nos dejó -pasmados- a la espera del ser. (Una perspectiva evolucionista esperaría otra cosa, de otra manera y con otro horizonte humano que el esencialista.)

\section{(Wittgenstein I)}

Para el primer Wittgenstein la esencia del ser humano era la misma que la del mundo: la lógica (entonces no había otra esencia). El mundo era la totalidad de los hechos y el sujeto la totalidad de las proposiciones. Pura lógica todo. El a priori eran las variables lógicas, en realidad una sola constante: la forma general de la proposición, que por su repetición sucesiva generaba todas las proposiciones del lenguaje y con ellas todos los hechos del mundo; y que era, por tanto, la misma esencia de ambos a la vez (e incluso una buena descripción de Dios) ${ }^{14}$. La lógica identificaba esencialmente mundo y lenguaje desde un trasfondo como de armonía preestablecida: "Wenn ein Gott eine Welt erschafft, worin gewisse Sätze wahr sind, so schafft er damit auch schon eine Welt, in welcher alle ihre Folgesätze stimmen. Und ähnlich könnte er keine Welt schaffen, worin der Satz ' $p$ ' wahr ist, ohne seine sämtlichen Gegenstände zu schaffen" (TR, 5.123). Está claro: a los hechos corresponden las proposiciones y a las palabras las cosas. Debido a esa armonía o identidad esencial lógica entre yo y mundo, no puede hablarse de antropocentrismo en el primer Wittgenstein. En tal caso hablaríamos de solipsismo: yo soy mi mundo, el mundo es mi mundo; solipsismo que, efectivamente, llevado hasta el (otro) extremo (de esa armonía o identidad) tiene que coincidir con el realismo ${ }^{15}$.

De modo que no ha lugar a cuestiones de si es el conocimiento el que se amolda a los objetos o los objetos al conocimiento, de si el centro es el sujeto o es el mundo. Simplemente: no hay sujeto de conocimiento y no hay otro mundo que yo. ¿Qué yo? Un yo solipsista que es el mundo, pero que no puede ser nada de lo que hay en él: no es un sujeto representante (nada hay que representar, todo lo soy yo); no es una entidad física (como cuerpo soy una cosa más en el mundo); ni una psíquica (el alma, como entidad compuesta, por ejemplo de representaciones, es un absurdo). Es un sujeto metafísico. ¿Qué es eso? Un yo que se agota en ser límite del mundo, que está coordinado por obra de Dios o de la naturaleza al mundo, pero que no está en él ni pertenece a él ${ }^{16}$. ¿Dónde está? Preguntar eso es como preguntar dónde está la lógica... Y si "la lógica llena el mundo", el sujeto, como límite del mundo, ha de ser también el límite de la lógica. Una lógica que, a su vez, también lo limita a él mismo: "Wir können nichts Unlogisches denken, weil wir sonst unlogisch denken müssten" (TR, 3.03). "Dass nicht unlogisch gedacht werden kann" (id., 5.4731) es el encierro. Un encierro en mí mismo. Decir que de la lógica no hay salida es decir que no hay salida del sujeto. Esta radicalidad poco tiene que ver con antropismos: yo soy el propio límite de mi encierro. Cuando la esencia se considera pura lógica el espesor metafísico casi desaparece. El sujeto está en

\footnotetext{
14 TR 5.471, 5.4711; cfr. 5.4731 y TB 1.8.16.

15 TR, 5.63, 5.64, 5.641.

${ }^{16} \mathrm{Cfr}$. para lo dicho hasta ahora en este párrafo: TR 5.631, 5.632, 5.641.
} 
ese lugar que es: el límite del mundo y de la lógica. Dentro de ellos no es nada, fuera tampoco.

En ese huis-clos solipsista el yo va encogiéndose progresivamente hasta hacerse un punto sin dimensión, hasta desaparecer, y sólo entonces aparece la realidad coordinada a él $(T R, 5.64)$. ¿No hay otro modo de salida que aparecer de otra forma? Eso no es salida. Habría que traspasar la barrera del punto donde realidad y sujeto se diluyen uno en otro. ¿Cómo? Como se ha hecho siempre: recurriendo a Dios, un recurso al infinito. O como ahora se puede hacer: volviendo la vista a lo animal de nuestra condición, a comprender que esa armonía o coordinación lógicas entre el yo y el mundo no es nada extraña, se ha generado en la adaptación evolutiva al mundo, el mundo de algún modo está en él, está en mi cerebro porque mi cerebro es (biológicoadaptativamente) mundo. El solipsismo puede verse así de otra forma: desde aquel punto o momento evolucionista en que realidad y sujeto, mundo y cerebro, no se diluyen uno en otro, sino se construyen juntos. La armonía o coordinación no sería nada extraño: es genética.

\section{(Wittgenstein II)}

Si en el primer Wittgenstein todo lo decible o pensable era lógico, en el segundo ese todo es gramatical. Más que encerrado en algo, o en todo, sea la lógica o la gramática, Wittgenstein se encerró siempre en la conciencia de encierro, es decir, en sí mismo. Llamemos "logocentrista" la segunda forma de encierro wittgensteiniana: el encierro en las palabras. El lenguaje (no el mundo) es el dato originario del ser humano, y de él no hay salida. La dispersión absoluta de los juegos de lenguaje, que son innumerables, obliga a buscar incesantemente su justificación porque, si no, todo el montaje pende en el aire. Y justificación última no hay ninguna. Así que o se juega eternamente con la mala conciencia de que el pensar o la vida es un juego a jugar nada más, o alguna vez hay que parar ese juego de conciencia. ¿Parar dónde? Lo mismo de antes pero al contrario: si antes Wittgenstein dejó todo el aparato lógico de mundo-yo, yo-mundo, encerrado en sí mismo y parece que la salida del pensar fue a un mundo inefable y eterno de valores estéticos, éticos y religiosos (más bien, pues, en dirección a Dios, al que nunca llegó), ahora parece que el animal es el representante perfecto de ese silencio eterno, ahora lo místico es lo animal. Si del círculo lógico se salía progresando al infinito de una intuición o sentimiento sub specie aeterni del mundo, del círculo gramatical se sale regresando no al infinito sino simplemente muy lejos en la línea de la evolución real del mundo.

(Pero tampoco hay por qué insistir hasta el detalle en la explicación evolutiva, que pertenece a otro modo de pensar que el filosófico y en éste tiene una validez relativa. Basta que esa hipótesis general quede, en general, en la consciencia filosófica $^{17}$. En filosofía las cosas se ven a otra luz y no son tan

17 Aunque tan modesta como sinceramente creo que en filosofía es mejor mantener las hipótesis científicas algo así como entre velo y desvelo, a media luz, no en primer plano del escenario de la Lichtung filosófica, donde esas hipótesis resultan extraños personajes con 
sencillas. La hipótesis científica evolucionista vale más crítica (frente a esencialismos) que explicativamente (como verdad) en filosofía. El encierro y la posibilidad de salida no se puede entender de otro modo que el filosófico. De otro modo es hasta una cuestión ridícula.)

Para leer Über Gewissheit (pensamientos que Wittgenstein escribió en su último año y medio de vida; más de la mitad, desde el \&300, los tres últimos meses antes de su muerte, solo en una habitación en casa de su médico, donde fue a esperarla) es oportuno orientarse en principio con estas señales de camino: 1. "Olvida esa seguridad trascendental inherente a tu concepto de espíritu" $(\& 47)^{18}$. 2. "Lo difícil es reconocer la falta de fundamento de nuestra creencia" (\&166). 3. "La fundamentación tiene un final" (\&563).

El que la filosofía del segundo Wittgenstein, sobre todo la última, tenga una pendiente instintiva es conocido, incluso referido explícitamente a ÜG ${ }^{19}$. Parece

extraños papeles, por otra parte es verdad que se prestan a juegos o planteamientos filosóficos interesantes. Como éstos, por ejemplo:

(1) Si, como hemos hecho, asimilamos el encierro lógico solipsista a la evolución biológica del período protorracional (desde hace dos millones y medio hasta hace cuarenta mil años, recordemos), la hipótesis evolucionista nos daría pie para perfilar como muy difícil la salida de ese círculo. Es difícil, diríamos, salir de ese cerebro paleolítico, que dedica un $90 \%$ de su volumen a la re-flexión, cuyas vías de comunicación interna (de autorreferencia) superan a las de comunicación externa (de referencia al exterior) en una proporción gigantesca: de los mil billones de fibras nerviosas que se supone hay en el cerebro sólo una de cada cien millones lleva fuera. (De todos modos nos quedarían diez millones de posibilidades de huída.)

(2) Planteando la salida de otro modo: ¿dónde situar lo animal wittgensteiniano, esa paz del pensar y esa seguridad del saber imaginadas más allá de cualquier justificación racional? ¿Basta llegar al nivel de conciencia de los homo protoculturales cuaternarios (en terminología de antes), o recurrimos a los homínidos terciarios, o perseguimos de verdad lo animal hasta los mamíferos, siempre con la esperanza de encontrar el punto exacto a traspasar: aquél donde comienza la no-paz wittgensteiniana? ¿O comienza con las construciones metafísicas de las grandes culturas y por tanto hay que dar un paso atrás de sólo 6.000 años?

(3) Y, además (si no es el último caso): ¿por qué no buscar rastros neuronales de esa paz wittgensteiniana, rastros genéticos? Igual que se buscan del gusto por lo estético se podían buscar los del placer filosófico de la definitiva abstención de juicio: las huellas genéticas de la epoché, apatheia, ataraxía.

(4) El esfuerzo del aprendizaje se premia con la velocidad en la evolución cultural, pero podría plantearse también que es precisamente esta velocidad la causa del estrés intelectual de espíritu, del encierro en una reflexividad cada vez más acelerada, y que como salida se requeriría volver al "tempo del caracol" de la evolución biológica protocultural.

(5) O que es la generalidad, en algún momento ya metafísicamente indiscriminada del cerebro (devenido "eine generelle Problemlösungsmaschine" en la misma época de su esplendor reflexivo), el origen de la tensión del pensar. Y que, si "los seres humanos son primates que se han desarrollado hasta generalistas" (M3, 13), como escribe Welsch, se trata, por tanto, de regresar (imaginariamente) a la condición de primate para encontrar en Ungrund (böhmeano), digamos.

${ }^{18} \mathrm{Si}$ a partir de ahora arriba no se cita la fuente, el párrafo es de ÜG.

${ }^{19}$ Por ejemplo: "It is part and parcel of the view of knowledge advanced in On Certainty that we shall not understand the nature of human knowledge until we grasp how human intelligence develops out of animal instinct". Así comienza Allan Janik su interesante artículo "From Logic to Animality or How Wittgenstein Used Otto Weininger", que trata de la posible influencia en la vida y en la filosofía de Wittgenstein de la "retórica de la ciencia" de Hertz y de la "psicología del animal" de Weininger. (Nómadas, Revista crítica de ciencias sociales y jurídicas, 4, juliodiciembre 2001, texto on line en: Theoria: Portal Crítico de Ciencia Social, http://www.ucm.es/info/nomadas/4/ajanik2.htm.) No existe otra edición por ahora. 
que a Witgenstein le fue interesando cada vez más lo instintivo, quizá porque no viera otro modo de hacer pie en algo. En 1948 escribe: "No olvidemos: también nuestras reflexiones más sutiles, más filosóficas tienen una base instintiva. Por ejemplo el 'Nunca se puede saber...' El quedar abierto a nuevos argumentos. Personas a las que no se les pudiera enseñar esto nos parecerían intelectualmente retrasadas. Todavía incapaces de formar un determinado concepto" (VB 138). Tras las leyes del juego gramatical no se ocultan nada más que rutinas aprendidas (eso es la lógica ahora) y un sujeto entrenado en ellas. $Y$ eso tiene una base instintiva.

Será un retrasado mental, en efecto, quien no sea capaz de desarrollar su base instintiva en el aprendizaje, pero el que es capaz, es decir, el ser humano normal, o el filósofo, tampoco es tanto ahora: un pobre sujeto amaestrado en un lenguaje y una forma de vida desde niño, que cuando se hace consciente del encierro del juego de lenguaje no puede encontrar otro sentido al juego entero más que el seguir jugando. Con la única conciencia liberadora de que así es su condición básica, seguramente heredada de hace millones de años. Eso justifica lo injustificable del juego. "So denken wir. So handeln wir. So reden wir darüber" (Zettel \&309). A ese modo final de actuar sólo podemos aludir con determinaciones mostrativas: "este" juego es el mío. O con complementaciones modales: "así" somos, hablamos, calculamos, actuamos. Definitivamente no hay ningún porqué, simplemente hago o no hago algo. Como la lógica antes, ahora "la praxis ha de hablar por sí misma"20, pero, igual que antes con la lógica, porque debajo de la praxis algo la sustenta y la coordina con el mundo.

Eso es todo, pero esa praxis del "así", efectivamente, encierra muchas más cosas que una evidencia empírica. La práctica humana y el ejercitarse en ella lleva más allá de su propio hecho. Que el juego de lenguaje se ratifique porque valga para algo y sea efectivo puede ser la "causa" de por qué se juega, pero no su "fundamento", su sentido último: por qué siquiera se juega (\&474). La causa lleva a lo racional, el fundamento a lo animal. El aprendizaje (Abrichtung) de los juegos revela un fondo animal, prehumano al menos ${ }^{21}$.

A pesar de conexiones neuronales o ejercitamiento en juegos de lenguaje, o precisamente por ello, sigue siendo un misterio cómo nacen los pensamientos. Desde luego no nacen con lógica, encuadrados en un contexto discursivo. Nacen libres, sueltos, como pinceladas improvisadas de un paisaje sin horizonte, como surgían en Wittgenstein. Sin el horizonte aún de la cultura (neolítica, digamos). Aunque aparezcan hoy en la era de la virtualidad surgen de lo profundo de la edad de piedra. ¿Cómo nace el lenguaje? Desde luego no nace de un razonamiento. Incluso nuestras reflexiones más sutiles tienen una base instintiva, recordemos. Para pensar y para hablar tampoco se necesita mucha lógica. La lógica es un lujo prescindible, a veces vano y a veces peligroso. Es mejor ver las cosas desde una perspectiva menos humana que la

\footnotetext{
20 ÜG \&139; cfr \&\$212, 148.

21 . "Das kindliche Verständnis der physischen Welt beruht auf der sicheren Grundlage der Primatencognition". (Michael Tomasello, Die kulturelle Entwicklung des menschlichen Denkens, edición alemana citada, p. 220.) Citado por Welsch $(M 3,6)$.
} 
demasiado humana de los entusiasmos visionarios, mostruos de la razón, etc. Por ejemplo: "Consideremos al ser humano como un animal; como un ser primitivo, al que se le presume instinto pero no razonamiento. Como un ser en un estado primitivo. Porque tampoco es que necesitemos avergonzarnos de qué lógica baste para un medio de entendimiento primitivo. El lenguaje no ha surgido de un razonamiento" (\&475). El lenguaje ha surgido de esa lógica primitiva, mínimamente necesaria, una lógica instintiva, anclada en lo profundo de la evolución biológica seguramente, pero más perceptiblemente anclada en la evolución ontogenética del individuo: amaestramiento en reglas y en seguirlas, que es lo mismo (una regla no se entiene, ni se puede entender, se cumple: ésa es su mejor y única comprensión).

Tengo un "sistema" o "edificio de convicciones" con el que, aunque sea inconscientemente, guarda de modo natural coherencia cualquier cosa de la que con convicción pienso o digo que "creo", "sé", "estoy convencido" de que es verdad. A él no se llega por razonamientos, está inconmoviblemente anclado "en todo mi preguntar y responder", en todos mis análisis y pruebas, no es sólo el punto de partida de todos nuestros argumentos sino que pertenece a la esencia misma de lo que llamamos un argumento: es su "elemento vital"22. Alguien dice saber algo y dice que es verdad: sí, pero es verdad "sólo en tanto es un fundamento inalterable de sus juegos de lenguaje", la completa seguridad con que lo dice "remite sólo a su criterio", a su actitud: "esa seguridad es la mía propia"23. ¿Y de dónde vienen esas seguridades, fundamentos, criterios? Está bien claro: "Es siempre por gracia de la naturaleza por lo que sabemos algo" (\&506)

La naturaleza tiene estructurado un montaje de la evidencia y el error fundado en supuestos y acciones ${ }^{24}$. Ese sistema de evidencias es un sistema de creencias que se va aprendiendo desde niño y cuya seguridad no proviene de que sean claras y evidentes, sino de que sean coherentes con lo que las rodea. Su seguridad depende, sobre todo, de que se aprenden para actuar. (He ahí el aprendizaje animal: el carácter animal de nuestra forma de construir sentido es precisamente este entretejer palabras y acciones indisolublemente ${ }^{25}$.) Es la praxis y la coherencia lo que produce ese sistema de evidencias no evidentes que son las creencias, lo que se cree. Lo que creemos depende de lo que aprendemos. Por ejemplo: "Desde niño he aprendido a juzgar así": eso es juzgar, incluso así he aprendido que determinada cosa es un juicio ${ }^{26}$.

Parece fácil y hasta obvio. Pero resulta difícil entender todo esto y admitirlo. Porque "la dificultad es darse cuenta de la falta de fundamento de nuestra creencia" (\&166). De que "en el fundamento de la creencia fundamentada está la creencia infundamentada" (\&253). De que no tiene justificación. No está en mi poder creer lo que creo, más bien parece que depende simplemente de "ein Naturgesetz des 'Fürwahrhaltens'". Que quizá el núcleo firme de nuestras creencias, verdades, razones, el armazón de todos nuestros pensamientos

\footnotetext{
${ }^{22}$ Cfr. ÜG \&\&102-104, 162, 185.

${ }^{23}$ Cfr. ÜG \&\&403/404, 174.

${ }^{24}$ Cfr. ÜG \&\&196, 254.

${ }^{25}$ Cfr. A. Janik, O. C., 9.

${ }^{26}$ Cfr. ÜG \&\& 128/129, 114, 115, 160, 263, 286.
} 
provenga de "tiempos inmemoriales". "(Todo ser humano tiene padres)". Efectivamente, y padres de padres... hasta lo inmemoriable. ${ }^{27}$

Resulta difícil entender esta falta de fundamento porque no gusta, gusta más el autoengaño, el recurso a la ilusión más allá de la naturaleza y sus leyes, más allá de nuestra propia condición básica. Ni más para atrás ni más para adelante tienen sentido las cosas. "No hay nada más difícil que no engañarse a sí mismo" (VB 71). ¿Por qué? Porque es difícil encontrar el comienzo, comenzar en el comienzo y no intentar retroceder más allá. En algún momento hay que dejar de pensar, retirar del tráfico el pensar y "desplazarlo a una vía muerta". La fundamentación tiene un final, y el final, como insinuábamos, "no es un presupuesto infundado sino un modo de acción infundado", no una evidencia inmediata sino nuestro modo de obrar, que está en la base del juego de lenguaje ${ }^{28}$. Nuestra condición.

Y eso es todo, aunque resulte difícil de entender, por más claro que esté. Antes, en 1937, quizá él mismo no lo tuviera tan claro, entonces le hubiera gustado discutir con Dios ${ }^{29}$, seguramente también sobre este montaje que ha hecho de las cosas. La seguridad del saber y la vida, que antes buscaba en la entrega, lógicamente imposible, a la fe cristiana en Dios, seguridad que nunca encontró porque se trataba de una lucha entre lo razonable (no creer) y lo no razonable (creer), y él no podía abdicar de la razón y la lógica en el absurdo, ahora la encuentra, más allá de esa dicotomía, disuelto ese modo de enfocar las cosas, concebida más allá de toda justificación, donde ya no puede haber absurdo: en lo animal. Esa seguridad ya "calmada" del saber ahora, cuando llega un punto en que ya no puede siquiera plantearse la duda, es forma de vida o una forma de vida. "Es decir, la consideraré como algo que queda más allá de lo justificado e injustificado; o sea, por así decirlo, como algo animal" (\&359). Ésta es la gran referencia de ÜG a lo animal.

Concluyamos con lo animal: tanto la forma de vida como el juego de lenguaje está anclado en un fondo de prácticas que remiten a algo animal, en cuanto algo que no plantea justificación posible. Que Wittgenstein admitiera concretar esto con los datos de las teorías evolucionistas actuales es más cuestionable, pero comentando su filosofía se puede hacer. Es una buena mezcla. Toda justificación definitiva de la razón más allá de ella, que no sea circular, recae en lo animal, sin que lo animal sea justificación alguna, sino un dato biológico de base que evita cualquier justificación. La falta de lógica o la lógica rudimentaria del animal es el único modo aproximativo de permanecer lógicos, es decir, sin pasmo metafísico, sin buscar justificaciones peregrinas. Su inconsciencia del juego es el único modelo aproximativo a seguir para permanecer conscientes de todo el armazón racional sin encerrarse en su círcculo. Los datos evolucionistas dan colorido a las ideas de Wittgenstein, éstas dan profundidad a esos datos.

\footnotetext{
${ }^{27}$ Cfr. ÜG \&\& 175, 173, 172, 211.

${ }^{28}$ Cfr. ÜG \&\& 471, 210, 563, 110, 204.

${ }^{29}$ Cfr. L. W., Denkbewegungen. Tagebücher 1930-1932/1936-1937, Innsbruck: Haymon-Verlag 1997, 96 (17.3.37): "Ich möchte mit Gott rechten"; cfr. 137 (17.4.37).
} 
Hablamos de "animal", pero podíamos también hablar de "Dios". ¿Por qué a la última seguridad de que venimos hablando, más allá de la razón y sinrazón, a la definitiva evidencia del conocimiento, a su fundamento más allá de su juego, no llamarla "Dios" si cumple todos sus atributos? Puedo perfectamente pensar que es Dios quien me revela o me enseña esas cosas de las que estoy seguro, quien evita que me engañe (\&361). ¿Por qué no? El buen Dios, al menos conceptualmente, es simplemente una metáfora del oscuro origen, que no puede ser, además, más que oscuro. "¿Está implicado Dios en mi saber? ¿Pueden algunos enunciados no ser falsos? Eso es lo que nos gustaría decir" (\&436). Pero parece que al final Dios no es ninguna hipótesis válida, Dios está fuera del juego, fuera del contexto del saber y hablar humanos, ni siquiera en sus límites, seguramente hay cosas que sé de las que Dios mismo no me podría contar nada (\&554). Dios no puede estar sujeto a mi saber, comprometerse con él hasta ese punto. Dios puede no estar en el juego, pero sí haciéndonos jugar así: si se admite su hipótesis o se juega con ella, él al fin y al cabo es el responsable de todo... Nos gustaría decir todo eso y también lo contrario. (No hay forma de entenderse ni de entender claramente en este aspecto a Wittgenstein. Parece que, en definitiva, sigue pensando que aceptar o no la hipótesis del Dios que revela ciertas verdades básicas y evita que nos engañemos es una decisión; que él tampoco al final de su vida pudo tomar, probablemente ni en un sentido ni en otro.)(\&362) Pero parece que lo animal está más cerca de nosotros que Dios, sobre todo a la vista de los datos de la ciencia. (Somos animales y no dioses: la de Dios es una bella hipótesis totalmente gratuita, demasiado infundada para superar la alternativa fundamento/no fundamento, digamos.) En este sentido Dios está fuera del juego humano. Mejor dicho: Dios está fuera del juego animal. Lo animal es el juego mismo: las reglas básicas de juego que hay hundidas en nuestra condición.

¿Y lo infantil? Lo infantil soy yo mismo comenzando el juego. Acabemos dejando las cosas en el niño, porque la condición infantil tiene las mismas ventajas conceptuales de paz que la animal (y la divina). Hemos sido niños hace poco y animales hace mucho. Pero igual que seguimos siendo una cosa seguimos siendo otra, que, por lo que interesa aquí, son la misma. Si la ontogénesis reproduce en cierto modo la filogénesis, en el niño ha de aparecer de algún modo la animalidad primordial. El niño es condicionado al juego, amaestrado (abgerichtet) en él, no sabe que juega, ni tiene ni necesita capacidad para preguntarlo. Como el gato, por ejemplo: "¿Cree el niño que hay leche? O ¿sabe que hay objetos físicos? ¿Sabe el gato que hay un ratón?" (\&478) O como el perro: "Ein Hund könnte lernen, auf den Ruf ' $N$ ' zu N zu laufen und auf den Ruf 'M' zu M - ¿sabría por eso cómo se llaman esas personas?" (\&540). El niño no aprende que haya o no, o que existan o no, libros, sillones, etc., aprende a coger libros, a sentarse en un sillón, etc.; no sabe que esto es su mano, y menos se plantea la posibilidad de que lo sea o no, aprende los innumerables juegos de lenguaje que se ocupan de su mano (\&\&476s., 374). "Diría que el niño aprende a reaccionar así y así; y si hace algo ahora, no por ello sabe de qué se trata. El saber comienza sólo a un nivel posterior" (\&538). El niño, pues, ni cree, ni sabe, ni duda, etc. En principio sucede como con el animal, luego se despierta a la razón y aparecen los problemas, deja de ser animal y abandona la paz del pensar... La mayor 
desgracia del hombre no es haber sido niño (Descartes), sino haber dejado de serlo. $\mathrm{Y}$ tener que buscar desesperadamente fundamentaciones. Para el pensar y la vida, es decir, para todo, baste definitivamente ésta (última, definitiva, animal): "Tienes que pensar que el juego de lenguaje... no está fundamentado. No es racional (ni irracional). Está simplemente ahí - como nuestra vida" (\&559). Eso escribe Wittgenstein el 19.4.51, 10 días antes de su muerte. A él le bastó, o por lo menos fue la última y definitiva.

Lo humano y lo animal: el encierro y la apertura, respectivamente, la tensión y la paz. Animal, niño o Dios: ése es el área de salida y descanso de lo humano. Los tres son los personajes de la octava elegía de Rilke.

Mit allen Augen sieht die Kreatur das Offene. Nur unsre Augen sind wie umgekehrt und ganz um sie gestellt als Fallen, rings um ihren freien Ausgang. Was draußen ist, wir wissens aus des Tiers Antlitz allein; denn schon das frühe Kind wenden wir um und zwingens, daß es rückwärts Gestaltung sehe, nicht das Offne, das im Tiergesicht so tief ist. Frei von Tod. Ihn sehen wir allein; das freie Tier hat seinen Untergang stets hinter sich und vor sich Gott, und wenn es geht, so gehts in Ewigkeit, so wie die Brunnen gehen. (...) Wäre Bewußtheit unsrer Art in dem sicheren Tier, das uns entgegenzieht in anderer Richtung -, riß es uns herum mit seinem Wandel. Doch sein Sein ist ihm unendlich, ungefaßt und ohne Blick auf seinen Zustand, rein, so wie sein Ausblick. Und wo wir Zukunft sehn, dort sieht es Alles und sich in Allem und geheilt für immer. ${ }^{30}$

¿Quién explica más, por cierto, en este caso: Darwin o Rilke?

\footnotetext{
${ }^{30}$ Rainer Maria Rilke, Die Duineser Elegien, achte Elegie, 7./8.2.1922, Château de Muzot.
} 